\title{
Homocysteine Levels in Chronic Gastritis and Other Conditions: Relations to Incident Cardiovascular Disease and Dementia
}

\author{
Stefan Redéen · Anna Ryberg · Fredrik Petersson • \\ Olle Eriksson $\cdot$ Katarina Nägga $\cdot$ Kurt Borch
}

Received: 4 October 2008/Accepted: 3 February 2009/Published online: 7 March 2009

(c) The Author(s) 2009. This article is published with open access at Springerlink.com

\begin{abstract}
Background Homocysteine levels in circulation are determined by several factors and hyperhomocysteinemia is reportedly associated with cardiovascular diseases and dementia. The aim of this study is to determine the relation of chronic gastritis and other conditions to homocysteine levels and their relation to incident cardiovascular diseases and dementia. Methods An adult population-based cohort $(N=488)$ was screened for $H$. pylori infection, gastro-duodenitis (endoscopic biopsies), disease history, and lifestyle factors. Blood samples were analyzed for pepsinogen I and II (gastric function), vitamin B12, folate, homocysteine, and cystatin $\mathrm{C}$ (renal function). The methylenetetrahydrofolate reductase C677T polymorphism reportedly associated with hyperhomocysteinemia was analyzed by pyrosequencing. Incident cardiovascular diseases and dementia were monitored during a median follow-up interval of 10 years. Results At baseline, there was a positive relation of S-homocysteine to male gender, age, S-cystatin $\mathrm{C}$, methylenetetrahydrofolate reductase 677TT genotype and atrophic gastritis. During follow-up, cardiovascular diseases occurred in 101/438 and dementia in 25/488 participants, respectively. Logistic regression analysis (adjusting for gender, age at baseline, follow-up
\end{abstract}

S. Redéen · A. Ryberg $\cdot$ K. Nägga $\cdot$ K. Borch $(\bowtie)$

Department of Clinical and Experimental Medicine,

Faculty of Health Sciences, University of Linköping,

Linköping 581 85, Sweden

e-mail: kurt.borch@liu.se

O. Eriksson

Department of Computer and Information Science, Faculty of Arts and Sciences, University of Linköping,

Linköping, Sweden

F. Petersson

Department of Pathology, Ryhov Hospital, Jönköping, Sweden interval, BMI, smoking, alcohol consumption, NSAID use, P-cholesterol, and P-triglycerides) showed an association of S-homocysteine higher than $14.5 \mu \mathrm{mol} / 1$ to cardiovascular diseases (OR 2.05 [95\% c.i. 1.14-3.70]), but not to dementia overall. Conclusions Gender, age, vitamin B12, folate, renal function, atrophic gastritis and the methylenetetrahydrofolate 677TT genotype were significant determinants of homocysteine levels, which were positively related to incident cardiovascular diseases.

Keywords Atrophic gastritis - Cardiovascular disease . Cohort - Cystatin C - Dementia - Folate - Gastritis · Homocysteine $\cdot$ H. pylori $\cdot$ Pepsinogen $\cdot$ Vitamin B12

\section{Introduction}

Homocysteine (Hcy) metabolism is dependent on several factors, such as $S$-adenosylmethionine (SAM), vitamin B12 as a cofactor, and methyltetrahydrofolate as the substrate. Deficiency of these or of other substances, as well as enzymatic defects, disturb the metabolism and may lead to hyperhomocysteinemia [1]. Methylenetetrahydrofolate reductase (MTHFR) catalyzes the reduction of 5, 10-methylenetetrahydrofolate to 5-methyltetrahydrofolate, acting as methyl donor in the conversion of Hcy to methionine [1]. The MTHFR single nucleotide polymorphism (SNP) C677T (SNPdb ID: rs1801133) is known to yield an enzyme with reduced activity, which leads to mild hyperhomocysteimia [2].

Hyperhomocysteinemia may cause damage to the intima of the vascular wall [3]. It has been linked to cardiovascular diseases, dementia, diabetes mellitus (DM), hypothyreosis, and renal disease [3-7]. The levels of Hcy in circulation are inversely related to renal function [8]. The 
association between Hcy and cardiovascular diseases $[9,10]$ and dementia $[11,12]$ has been shown in several studies, but is controversial $[13,14]$. The cut-off value for the Hcy concentration used to define hyperhomocysteinemia is poorly defined. Levels around $14-15 \mu \mathrm{mol} / \mathrm{l}$ have been used [3, 5, 7, 10-12, 15].

Deficiencies of vitamin B12 and folate are common etiologies of hyperhomocysteinemia. Untreated celiac disease is frequently associated with folate deficiency and, to a lower rate, with vitamin B12 deficiency $[16,17]$. A frequent cause of vitamin B12 deficiency is atrophy of the gastric corpus mucosa, which leads to reduced intrinsic factor secretion, i.e., latent or overt pernicious anemia. Helicobacter pylori (H. pylori) infection per se, irrespective of atrophy of the gastric mucosa, was found to be associated with reduced vitamin B12 in circulation [18, 19]. However, a meta-analysis showed no association of H. pylori infection to coronary heart disease [20].

The objective of this 10-year follow-up study of a population-based cohort was to investigate what impact H. pylori infection, chronic gastritis, MTHFR C677T SNP, renal dysfunction, and some other conditions have on variations in Hcy levels in circulation and, furthermore, to explore the relations of Hcy levels to subsequent development of cardiovascular diseases and dementia.

\section{Methods}

\section{Study Population and Follow-Up}

The study was performed in accordance with the Helsinki Declaration and was approved by the local ethics committee. Informed written consent was obtained from all participants.

The prevalence of gastritis, duodenitis, and H. pylori infection in this cohort have been published [21, 22]. Fivehundred-and-one randomly selected subjects (age 3585 years and equal number of women and men at selection) in the general population underwent esophago-gastroduodenoscopy (EGD) with biopsy. A complete histomorphological examination of biopsies from both the gastric corpus and antrum was obtained in 488 participants. These 488 participants make up the cohort studied here and which comprises 225 women and 263 men with median ages of 62 ( $\min 38-\max 85$ ) years and 60 (37-82) years, respectively, at baseline. Histomorphological examination of biopsies from the second part of the duodenum was achieved in 474 participants.

At baseline, the participants received a self-administered questionnaire exploring details about previous and current diseases, body weight, and height, current smoking, use of alcohol, and current medications including the use of aspirin (including low-dose) or other potentially ulcerogenic NSAIDs. Eight years (minimum) after baseline, the same questionnaire was distributed. In addition, in-hospital diagnoses recorded before and after baseline including causes of death among deceased participants were extracted from local patient files (including those of the Memory Reception, Department of Geriatric Medicine) as well as from the records of Statistics Sweden (SCB) and the Swedish National Board of Health and Welfare. Nationwide reporting to the latter goes back to 1964 (full cover by 1987). Files were screened up to 2005 .

In case of incident cardiovascular diseases, one diagnosis was assigned to each participant. Myocardial infarction was given the highest priority. The priority of other diagnoses in descending order was: ischemic heart disease (angina pectoris), aortic or other arterial aneurysm, transient ischemic attack (TIA) or stroke, and cardiac arrhythmia and/or heart failure; all without a registered diagnosis of myocardial infarction. Hypertension as the sole diagnosis was not included since primarily this diagnosis is set in primary health care, and is probably underreported and latent/subclinical in the general population.

In the total cohort of 488 participants, 50 had a history of a cardiovascular disease at baseline (myocardial infarction ten, angina pectoris 17, TIA/stroke four, and cardiac arrhythmia and/or heart failure 19). None had known dementia, since that precluded participation. Ninety-nine of 485 responders were current smokers, 78 of 476 responders used spirits and/or wine every week, and 81 of 476 responders used aspirin or other NSAID every week. There were 438 participants (207 women and 231 men, age 59.4 (36.8-84.9) years) with no history of a cardiovascular disease or dementia at baseline (smokers 93 of 435 responders; use of alcohol every week 71 of 429 responders; use of aspirin or other NSAID every week 60 of 427 responders).

At baseline, 14 participants had DM (one type 1 and 13 type 2). During the follow-up period, four developed type 2 DM. Twenty-six participants had thyroid disease, classified as hypothyroid disease in six. During follow-up, one participant underwent surgery for non-specified thyroid disease. Three participants had a history of renal disease (one operated and one non-operated for cystic disease, and one operated for renal carcinoma). During follow-up, nephritis was diagnosed in one and renal carcinoma in two participants.

\section{Histological Examinations and H. pylori Status}

Routinely prepared biopsy sections (three biopsies from the corpus, antrum and second part of the duodenum) were stained with hematoxylin-eosin, Alcian blue-periodic acidSchiff, and Giemsa stain as previously described [21]. Gastritis was classified according to the Sydney system, 
i.e., severity, topographic distribution and the occurrence of H. pylori [23]. Considering glandular atrophy of the gastric corpus mucosa, moderate to severe atrophy was taken into account in the present study. Atrophy of the duodenal mucosa was histologically classified according to Alexander [24], and in the present study it was defined as grade III or grade IV.

An experienced pathologist (F.P) who had no information about other data performed the microscopic examinations.

H. pylori status was classified as previously described, i.e., positive if at least one of serology, histology and urease-test on fresh biopsy specimens [21] indicated infection. The study was non-interventional regarding H. pylori infection. However, the infection was treated at baseline in 15 participants who at screening were shown to have $H$. pylori associated ulcer disease [21]. None of these had atrophic gastritis.

\section{Blood Analyses}

At baseline, blood samples were collected in a fasting state immediately preceding EGD. The samples were stored at $-80^{\circ} \mathrm{C}$. Sera were analyzed (Biohit Diagnostics, Helsinki, Finland) for vitamin B12 (pmol/l), folate (nmol/l) and Hcy $(\mu \mathrm{mol} / \mathrm{l})$ concentrations with the Immulite ${ }^{\circledR} 1000$ method (DPC, Los Angeles, CA, USA) according to the manufacturer's instructions. Samples were run at the same time to minimize assay variability. Pepsinogens in serum were measured with a sandwich enzyme immunoassay (ELISA) utilizing a pepsinogen I (PGI) and pepsinogen II (PGII) specific capture antibody, respectively, and a horseradish peroxidase (HRP) detection antibody (from GastroPanel ${ }^{\circledR}$, Biohit Diagnostics, Helsinki, Finland). There is no cross reactivity between the two assays. The reference interval is 30.0-120.0 $\mu \mathrm{g} / \mathrm{l}$ for PGI, 3.0-10.0 $\mu \mathrm{g} / \mathrm{l}$ for PGII and 3.0-20.0 for the ratio PGI/PGII. Values of PGI/PGII lower than 3.0 were considered as indicative of significant atrophy of the gastric corpus mucosa.

P-total cholesterol (mmol/l) and P-triglycerides ( $\mathrm{mmol} / \mathrm{l})$ were measured with the Hitachi 717 (Boehringer Mannheim Scandinavia AB, Stockholm, Sweden) using specific reagent 1 .

Cystatin C in serum was analyzed with Advia 1650 (Bayer $\mathrm{AB}$, Gothenburg, Sweden) using reagent DakoCystatin $\mathrm{C}$ at the Dept. of Clinical Chemistry, University Hospital, Linköping, Sweden (reference interval for ages 1-50 years : $0.7-1.21 \mathrm{mg} / \mathrm{l}$ and for ages $>50$ years: $0.84-1.55 \mathrm{mg} / \mathrm{l}$ ).

\section{MTHFR SNP 677 Genotype Analysis}

DNA from blood samples (whole blood, plasma, or serum) was extracted, amplified and quality assessed as previously described [25]. Primers for MTHFR C677T (rs1801133) pyrosequencing analysis were designed based on the available MTHFR genomic sequence (GenBank accession number NT_021937, region: 6388104-6400540) using the PSQ Assay design software (Biotage, Uppsala, Sweden). The primers Biotin-MTHFR677.se (ccgaagcagggagctttga), MTHFR677.as (caagtgatgcccatgtcg), and sequencing primer Seq-MTHFR677 (cgtgatgatgaaatcg) were used. PCR products were obtained using the HotStarTaq Plus Mastermix kit (Qiagen, Hilden, Germany) following the manufacturer's instructions, using 5 pmol of each primer, and the PCR program: $95^{\circ} \mathrm{C} 5 \mathrm{~min} ; 35$ cycles of $95^{\circ} \mathrm{C} 30 \mathrm{~s}$, $60^{\circ} \mathrm{C} 30 \mathrm{~s}, 72^{\circ} \mathrm{C} 1 \mathrm{~min}$; final extension $72^{\circ} \mathrm{C} 10 \mathrm{~min}$. The PCR products were analyzed by pyrosequencing as previously described [25].

\section{Statistical Analyses}

Numerical data were summarized as median (min-max) unit. The Mann-Whitney U-test was used for comparisons of continuous data between groups while Fisher's exact test was used for dichotomous data. Correlations were tested with Spearman's rank correlation test. A general linear model (GLM) was used to identify factors with impact on S-Hcy concentrations. Logistic regression analysis was performed in which incident cardiovascular diseases overall or dementia overall were included as the dependent variable. Goodness-of-fit was tested with the HosmerLemeshow's method. Coefficients in GLM and odds ratios $(\mathrm{OR})$ in logistic regression are given with $[95 \%$ confidence intervals]. In every analysis, a two-sided $P$-value of $<0.05$ was regarded as significant.

\section{Results}

At baseline, 246 participants had histologically normal gastric mucosa with negative H. pylori status, 209 had chronic gastritis with positive $H$. pylori status, and 33 had chronic gastritis with negative $H$. pylori status. Atrophy of the corpus mucosa was diagnosed histomorphologically in 21 of the 488 participants ( 15 with positive H. pylori status). Twenty of 474 examined participants had a subnormal PGI/PGII value $(<3.0)$ and 28 of 475 participants had atrophy either according to histological examination and/or the PGI/PGII value. Villous atrophy of the duodenal mucosa was diagnosed in nine participants. The distribution of the MTHFR 677 genotype among 483 successfully analyzed participants was $50.1 \% \mathrm{CC}, 38.5 \% \mathrm{TC}$, and $11.4 \%$ TT while an S-Cystatin C concentration above the reference range was present in 18 of 473 participants examined. 
Table 1 S-Hcy concentrations in participants with condition reportedly associated with hyperhomocysteinemia

\begin{tabular}{lccc}
\hline Condition present at baseline & $\begin{array}{l}\text { No. of participants } \\
\text { examined }\end{array}$ & $\begin{array}{l}\text { P-homocysteine, } \mu \text { mol/l, } \\
\text { median (min-max) }\end{array}$ & $\begin{array}{l}P \text { (Mann-Whitney U-test) } \\
\text { when compared to participants } \\
\text { with none of these conditions }\end{array}$ \\
\hline $\begin{array}{l}\text { Diabetes mellitus } \\
\text { Hypothyreosis }\end{array}$ & 13 & $15.4(11.0-29.0)$ & 0.01 \\
$\begin{array}{l}\text { Renal dysfunction (S-cystatin } \\
\quad \text { C above reference range) }\end{array}$ & 17 & $10.6(9.6-14.4)$ & 0.23 \\
MTHFR 677 TT genotype & 51 & $16.4(9.4-29.6)$ & 0.01 \\
None of these conditions & 392 & $13.0(7.6-50.0)$ & 0.13 \\
\end{tabular}

${ }^{a}$ In nine samples, Cystatin C or MTHFR 677 could not be determined

Spearman analysis showed a weak although significant $(P<0.001)$ correlation between age and S-Hcy (rho $=$ $0.26)$, age and S-cystatin $\mathrm{C}($ rho $=0.40)$, S-Hcy and S-cystatin C (rho =0.22), S-vitamin B12 and S-Hcy (rho $=-0.28)$ and S-folate and S-Hcy (rho $=-0.24)$.

S-Hcy concentrations were lower in women than in men (12.0 (2.9-35.7) $\mu \mathrm{mol} / 1$ vs 13.9 (5.8-50.0) $\mu \mathrm{mol} / \mathrm{l} ; 222$ women and 257 men were examined; $P<0.001)$ and $\mathrm{S}-$ vitamin B12 concentrations were higher in women than in men (288 (118-789) pmol/l vs. 259 (98-742) pmol/l; 208 women and 233 men were examined; $P=0.005)$. S-folate and $\mathrm{S}$-cystatin $\mathrm{C}$ concentrations did not differ between the sexes.
S-Hcy concentrations were elevated in participants with DM and in those with elevated S-cystatin C (Table 1). Table 2 shows that S-Hcy concentrations were increased among participants with atrophic gastritis, but not in those with $H$. pylori-associated gastritis without atrophy. Considering participants with subnormal PGI/PGII, indicative of atrophy of the gastric corpus mucosa, results were similar with median S-Hcy 17.5 (9.8-50.0) $\mu \mathrm{mol} / \mathrm{l}$ among participants with subnormal PGI/PGII and 12.5 (2.933.1) $\mu \mathrm{mol} / 1$ among those with PGI/PGII within normal range $(P<0.001)$.

S-Hcy levels did not differ significantly between participants with the MTHFR 677 TT genotype (13.0

Table 2 S-vitamin B12, S-folate, and S-homocysteine concentrations in relation to histomorphology in the gastric and duodenal mucosa at baseline

\begin{tabular}{|c|c|c|c|}
\hline Gastro-duodenal histomorphology & $\begin{array}{l}\text { Vitamin B } 12, \mathrm{pmol} / 1 \\
\text { Median }(\min -\max ) \\
\text { no. examined } \\
\mathrm{P}\end{array}$ & $\begin{array}{l}\text { Folate, } \mathrm{nmol} / \mathrm{l} \\
\text { Median (min-max) } \\
\text { no. examined } \\
\mathrm{P}\end{array}$ & $\begin{array}{l}\text { Homocysteine, } \mu \mathrm{mol} / 1 \\
\text { Median }(\min -\max ) \\
\text { no. examined } \\
\mathrm{P}\end{array}$ \\
\hline \multirow[t]{3}{*}{ Normal gastric mucosa without H.pylori infection } & $266(118-663)$ & $9.9(2.1-35.2)$ & $12.2(2.9-33.1)$ \\
\hline & 220 & 215 & 242 \\
\hline & - & - & - \\
\hline \multirow{3}{*}{$\begin{array}{l}\text { H. pylori-associated chronic gastritis } \\
\text { without significant atrophy of the corpus } \\
\text { mucosa }\end{array}$} & $282(98-789)$ & $9.0(3.1-36.3)$ & $13.1(4.8-35.7)$ \\
\hline & 179 & 175 & 190 \\
\hline & $0.72^{\mathrm{a}}$ & $0.21^{\mathrm{a}}$ & $0.06^{\mathrm{a}}$ \\
\hline \multirow{3}{*}{$\begin{array}{l}\text { Non- } H \text {. pylori-associated chronic gastritis } \\
\text { without significant atrophy of the corpus } \\
\text { mucosa }\end{array}$} & $281(161-575)$ & $12.1(5.1-30.0)$ & $12.0(8.7-21.2)$ \\
\hline & 27 & 24 & 27 \\
\hline & $0.86^{\mathrm{a}}$ & $0.08^{\mathrm{a}}$ & $0.50^{\mathrm{a}}$ \\
\hline \multirow{3}{*}{$\begin{array}{l}\text { Chronic gastritis with atrophy of the corpus } \\
\text { mucosa with or without } H \text {. pylori infection }\end{array}$} & $269(107-497)$ & $9.6(4.0-24.2)$ & $20.1(10.2-50.0)$ \\
\hline & 15 & 19 & 20 \\
\hline & $0.14^{\mathrm{a}}$ & $0.61^{\mathrm{a}}$ & $<0.001^{\mathrm{a}}$ \\
\hline \multirow{3}{*}{$\begin{array}{l}\text { No significant villous atrophy } \\
\text { of the duodenal mucosa }\end{array}$} & $269(98-789)$ & $9.6(3.1-36.3)$ & $12.7(2.9-50.0)$ \\
\hline & 430 & 422 & 467 \\
\hline & - & - & - \\
\hline \multirow{3}{*}{$\begin{array}{l}\text { Villous atrophy of the duodenal mucosa } \\
\text { (Alexander grade III to IV) }\end{array}$} & $319(224-603)$ & $6.1(2.1-12.8)$ & $13.9(8.5-33.1)$ \\
\hline & 8 & 8 & 9 \\
\hline & $0.16^{\mathrm{b}}$ & $0.02^{\mathrm{b}}$ & $0.47^{\mathrm{b}}$ \\
\hline
\end{tabular}

${ }^{a} P$-value from the Mann-Whitney U-test when compared to participants with normal gastric mucosa

b $P$-value from the Mann-Whitney U-test when compared to participants with mild or no villous atrophy of the duodenal mucosa 
Table 3 General linear model estimates of factors with putative impact on Shomocysteine concentration (dependent variable)

\begin{tabular}{lccc}
\hline Independent variable & Coefficient & $\begin{array}{l}95 \% \text { confidence } \\
\text { interval (min-max) }\end{array}$ & $P$ \\
\hline Male gender & & $0.65-2.49$ & 0.001 \\
Age & 1.57 & $0.0-0.13$ & 0.001 \\
BMI & 0.08 & $-0.17-0.10$ & 0.62 \\
Diabetes mellitus & -0.03 & $-0.42-5.46$ & 0.09 \\
Hypothyreosis & 2.52 & $-2.92-4.60$ & 0.66 \\
S-cystatin C & 0.84 & $1.26-4.15$ & $<0.001$ \\
S-vitamin B12 & 2.71 & $-0.01-0.00$ & $<0.001$ \\
S-folate & -0.01 & $-0.24--0.08$ & $<0.001$ \\
MTHFR 677 TT genotype & -0.16 & $0.27-3.02$ & 0.02 \\
Atrophy of the gastric corpus mucosa & 1.645 & $2.00-7.24$ & 0.001 \\
Atrophy of the duodenal mucosa & 4.62 & $-0.75-5.76$ & 0.13 \\
$\quad$ Alexander grade III-IV) & 2.50 & &
\end{tabular}

(7.6-50.0) $\mu \mathrm{mol} / \mathrm{l})$ and those with the CT (12.7 (4.833.1) $\mu \mathrm{mol} / \mathrm{l})$ or CC genotype (12.7 (2.9-48.3) $\mu \mathrm{mol} / \mathrm{l})$, nor was there any relation between S-Hcy levels and the presence of the T allele $(12.8(4.8-50.0) \mu \mathrm{mol} / \mathrm{l})$.

GLM analysis (Table 3) showed that S-Hcy concentrations were related to gender, age, S-cystatin C, S-vitamin B12, S-folate, MTHFR 677 TT genotype, and the occurrence of atrophic gastritis. Substituting the morphological diagnosis of atrophic gastritis in Table 3 for subnormal PGI/PGII yielded similar results overall and the coefficient for subnormal PGI/PGII was 5.96 (95\% c.i. 3.35-8.56, $P<0.001)$. When $H$. pylori-associated chronic gastritis without significant atrophy of the corpus mucosa was included in the model, no significant relation to S-Hcy was shown.

At baseline, 438 participants had no history of any cardiovascular disease. They were followed-up for 129 (9178) months (4,796 person years), during which 101 were diagnosed with cardiovascular disease. These were myocardial infarction [28], angina pectoris [17], abdominal aortic aneurysm [6], TIA/stroke [18], and cardiac arrhythmia/heart failure [32]. The median follow-up time for all
488 participants was 128 (1-180) months $(5,262$ person years). Among all 488 participants, 25 developed dementia. In six, the form of dementia was classified as Alzheimer's disease, in three as vascular dementia, in six as mixed dementia, and in ten it was not classified. Mild cognitive impairment (diagnosed in five participants) was not defined as dementia.

The prevalence of atrophic gastritis was 9/101 among participants with incident cardiovascular diseases and 7/337 among participants not diagnosed with any cardiovascular disease during follow-up $(P=0.004)$. Corresponding figures for dementia were $3 / 25$ and $18 / 463$, respectively $(P=0.09)$. The prevalence of positive $H$. pylori status did not differ significantly between participants with and without incident cardiovascular diseases or dementia.

S-Hcy was found to be elevated among participants developing cardiovascular diseases (14.4 (4.6-37.3) $\mu \mathrm{mol} /$ 1) compared to those without such diseases (12.1 (2.948.3) $\mu \mathrm{mol} / \mathrm{l})(P=0.001)$. S-Hcy levels in subgroups are shown in Table 4.

The median for S-Hcy was $15.7(11.2-28.4) \mu \mathrm{mol} / \mathrm{l}$ among participants developing dementia and 12.7 (2.9-

Table 4 S-homocysteine concentrations at baseline in participants diagnosed with cardiovascular diseases during follow-up

\begin{tabular}{|c|c|c|c|}
\hline Diagnosis & $\begin{array}{l}\text { No. of participants } \\
\text { examined }\end{array}$ & $\begin{array}{l}\text { S-homocysteine, } \mu \mathrm{mol} / \mathrm{l} \\
\text { median }(\min -\max )\end{array}$ & $\begin{array}{l}P \text {-value }{ }^{\mathrm{a}} \text { when compared to participants } \\
\text { with no known cardiovascular disease }\end{array}$ \\
\hline $\begin{array}{l}\text { No known cardiovascular disease } \\
\text { (hypertension disregarded) }\end{array}$ & 331 & $12.1(2.9-48.3)$ & \\
\hline Myocardial infarction & 26 & $15.1(8.7-37.3)$ & $<0.001$ \\
\hline Ischemic heart disease (angina pectoris) & 17 & $13.0(7.3-25.6)$ & 0.24 \\
\hline Aortic Aneurysm & 5 & $21.0(10.7-24.2)$ & 0.02 \\
\hline TIA or stroke & 18 & $11.7(4.6-35.7)$ & 0.91 \\
\hline Cardiac failure and/or arrhythmia & 32 & $13.2(6.9-28.4)$ & 0.15 \\
\hline
\end{tabular}

${ }^{a}$ Mann-Whitney U-test 
Table 5 Associations of S-Hcy levels with risk of cardiovascular diseases grouped together (A) and dementia subgroups considered together (B) as the dependent variable

\begin{tabular}{lll}
\hline Cut-off level for S-Hcy & \multicolumn{2}{l}{ Odds ratio [95\% confidence interval] } \\
\cline { 2 - 3 } & A & B \\
\hline $14.0 \mu \mathrm{mol} / 1$ & $1.81[1.01-3.23]$ & $1.50[0.50-4.46]$ \\
$14.5 \mu \mathrm{mol} / 1$ & $2.05[1.14-3.70]$ & $1.92[0.64-5.79]$ \\
$15.0 \mu \mathrm{mol} / 1$ & $1.74[0.96-3.16]$ & $1.90[0.63-5.68]$ \\
None (S-Hcy continuous) & $1.06[1.00-1.12]$ & $1.09[0.99-1.20]$ \\
\hline
\end{tabular}

Results are from logistic regression analysis adjusting for gender, age at baseline (years), follow-up interval (months), body mass index $\left(\mathrm{kg} / \mathrm{m}^{2}\right.$ ), current smoking (yes/no), alcohol use (weekly use yes $/ \mathrm{no}$ ), use of NSAID (weekly use yes/no), P-total cholesterol (mmol/l) and P-triglycerides $(\mathrm{mmol} / \mathrm{l})$

50.0) $\mu \mathrm{mol} / \mathrm{l}$ among participants without dementia $(P=0.004)$. With regard to the subgroups, S-Hcy was 20.0 (12.0-23.1) $\mu \mathrm{mol} / 1$ in vascular dementia, 16.2 (12.225.3) $\mu \mathrm{mol} / 1$ in Alzheimer's disease, 11.9 (11.2-12.5) $\mu \mathrm{mol} / \mathrm{l}$ in mixed dementia and 16.7 (12.2-28.4) $\mu \mathrm{mol} / \mathrm{l}$ in non-specified dementia. The difference of their S-Hcy levels in relation to participants without dementia was close to significant for Alzheimer's disease $(P=0.05)$ and significant for non-specified dementia $(P=0.004)$.

Table 5A shows the results of the logistic regression analyses with cardiovascular diseases considered together as the dependent variable and S-Hcy as a continuous or dichotomous independent variable with different cut-off levels. Exchanging S-Hcy in this model for gastric mucosal atrophy (as determined morphologically or with PGI/PGII), MTHFR 677 TT genotype and elevated cystatin C taken together as an independent variable, showed no significant relation to cardiovascular diseases (OR 1.70 [0.92-3.13] with morphological determination). As shown in Table 5B, there was no significant association between S-Hcy and subgroups of dementia considered together.

\section{Discussion}

As is the case with most population-based cohorts, one may question whether the present one is representative. The incidence of myocardial infarction found was at approximately the same level as reported by the Swedish National Board of Health and Welfare (www.socialstyrelsen.se). Also, the incidence of dementia was at the same level as previously reported in Sweden [26]. However, considering the invasive character of the EGD, which the participants were asked to undergo, the participation rate became relatively low and there may have been a selection bias based on the occurrence of digestive symptoms [21].

A strength of the study is its long follow-up interval of 10 years overall (4,796 person years for cardiovascular disease and 5,262 person years for dementia) and that, in addition to relations of Hcy to disease development, it includes main determinants of Hcy levels. The evaluation of these relations was enhanced by the access to data on known relevant confounders. Another strength of the study is the reliability of the files of the Swedish National Board of Health and Welfare in which personal identification numbers are linked to in-hospital diagnoses (www.social styrelsen.se) and, furthermore, that the information obtained from these files was verified or supplemented by information from the local hospital files and by the participants themselves.

Regarding determinants of Hcy levels in circulation, the GLM analysis showed a positive relation of S-Hcy to age, male gender, MTHFR 677 TT genotype and atrophic gastritis (both as determined morphologically and functionally with PGI/PGII). Not unexpectedly, there was a negative relation of S-Hcy to renal function, S-vitamin B12, and S-folate. These findings are in accord with those in other studies [2, 16, 17, 27-31], although no single study evaluated all these parameters. We found no significant association between the MTHFR 677 TT genotype and Hcy levels in the univariate analysis. This is not in agreement with a previous study showing an association with mild hyperhomocysteinemia [1]. However, recent studies have shown a reduced effect of the MTHFR 677 TT genotype in populations with high folate intake $[32,33]$. In the GLM analysis in the present study, this SNP had a significant impact on Hcy levels. The appearance of this significance may be explained by the inclusion of S-folate in the model.

Inclusion in the GLM analysis of $H$. pylori-associated chronic gastritis without atrophy of the corpus mucosa did not show any significant relation to S-Hcy. This is in agreement with the finding of others, namely that $H$. pylori per se has no significant impact on Hcy levels [34, 35].

There was no significant relation of S-Hcy to the occurrence of atrophy of the duodenal mucosa, DM, or hypothyreosis in the GLM analysis. Others have found increased S-Hcy levels in these diseases [5, 6, 29]. Since the number of cases in these groups in the present study was small, we do not draw any conclusions regarding their impact on Hcy levels.

When using dichotomized values of S-Hcy with a cutoff level of $14.5 \mu \mathrm{mol} / 1$ we found a positive correlation between S-Hcy and the incidence of cardiovascular diseases; in fact, the risk was doubled (OR 2.05 [1.14-3.70]). With S-Hcy as continuous variable the relation was weaker (OR 1.06 [1.00-1.12]). Exchanging S-Hcy for its explanatory variables, atrophic gastritis, MTHFR 677 TT genotype and elevated cystatin $\mathrm{C}$ taken together as an independent variable in the analysis yielded a weak association, if any (OR 1.70 [0.92-3.13]). Since there are other 
causes of variations in Hcy levels than those studied here, this lack of an association is not unexpected.

Considering the relation of Hcy to cardiovascular diseases, our results are in accordance with findings in other prospective studies, although the cut-off levels for Hcy concentrations used vary between the studies [36-41]. In one of these studies [36], which included 229 cases and 1,126 controls (all men, mean follow-up time 8.7 years), there was a continuous dose-response relationship with a $41 \%(20 \%-65 \%)$ increased risk of death from ischemic heart disease for each 5- $\mu \mathrm{mol} / \mathrm{l}$ increase in the S-Hcy level. In an other study [37] of 122 cases and 478 controls, the relative risk of ischemic heart disease hospital discharges and deaths resulting from a $4 \mu \mathrm{mol} / 1$ increase in S-Hcy was 1.32 (1.05-1.65). Whincup et al. [41], who followed a population for 12.8 years ( 386 cases and 454 controls, men aged $40-59$ years at entry), found that a $47 \%$ increase in $\mathrm{S}$-Hcy was associated with a slight increase in the OR for myocardial infarction of 1.15 (1.00-1.32). For values of S-Hcy higher than $16.5 \mu \mathrm{mol} / \mathrm{l}$, the OR for myocardial infarction was 1.77 (1.28-2.42). As shown in the comprehensive meta-analysis conducted by the Homocysteine Studies Collaboration, there are also prospective studies that show no correlation of Hcy levels to cardiovascular diseases [40]. This was also the case in the study by Fallon et al. [42], which included 312 men with coronary heart disease and 1,248 matched controls.

Although according to the results of univariate analysis in the present study, S-Hcy levels seemed to be elevated in subgroups with dementia, including dementia overall as dependent variable in the logistic regression analysis yielded no significant association to Hcy levels. In a prospective study of 1,092 participants (667 women and 425 men) with a median follow-up interval of 8 years, Seshadri et al. [11] found that increased P-Hcy is an independent risk factor for dementia and Alzheimer's disease. The relative risk of dementia was 1.4 (1.1-1.9) for each increase of one SD in logarithmically transformed Hcy values. The corresponding figure for Alzheimer's disease was 1.8 (1.3-2.5). In an Italian dementia-free cohort of 816 participants, Ravaglia et al. [43] related baseline P-Hcy to incident dementia, including Alzheimer's disease, during a mean follow-up interval of 4 years. They concluded that increased Hcy and low folate concentrations are independent risk factors. Hyperhomocysteinemia was considered to be present with a P-Hcy higher than $15.0 \mu \mathrm{mol} / \mathrm{l}$. With this cut-off level the hazard ratio for dementia was 2.08 .

To summarize, in this population-based cohort Hcy concentrations in circulation were dependent on gender, age, the levels of vitamin B12 and folate, as well as on renal function, the occurrence of atrophic gastritis and the MTHFR 677 TT genotype. There was a positive relation of Hcy levels to incident cardiovascular diseases.
Acknowledgments This study was supported by grants from the Swedish Cancer Society and the Research Council in the South East of Sweden (FORSS).

Open Access This article is distributed under the terms of the Creative Commons Attribution Noncommercial License which permits any noncommercial use, distribution, and reproduction in any medium, provided the original author(s) and source are credited.

\section{References}

1. Selhub J. Homocysteine metabolism. Аnпи Rev Nutr. 1999; 19:217-246.

2. Frosst $\mathrm{P}, \mathrm{Blom} \mathrm{HJ}$, Milos R, et al. A candidate genetic risk factor for vascular disease: a common mutation in methylenetetrahydrofolate reductase. Nat Genet. 1995;10(1):111-113.

3. Prasad K. Homocysteine, a risk factor for cardiovascular disease. Int J Angiol. 1999;8(1):76-86.

4. Nilsson K, Gustafson L, Faldt R, et al. Hyperhomocysteinaemiaa common finding in a psychogeriatric population. Eur J Clin Invest. 1996;26(10):853-859.

5. Soinio M, Marniemi J, Laakso M, Lehto S, Ronnemaa T. Elevated plasma homocysteine level is an independent predictor of coronary heart disease events in patients with type 2 diabetes mellitus. Ann Intern Med. 2004;140(2):94-100.

6. Evrengul H, Tanriverdi $\mathrm{H}$, Enli $\mathrm{Y}$, et al. Interaction of plasma homocysteine and thyroid hormone concentrations in the pathogenesis of the slow coronary flow phenomenon. Cardiology. 2006;108(3):186-192.

7. van Guldener C. Why is homocysteine elevated in renal failure and what can be expected from homocysteine-lowering? Nephrol Dial Transplant. 2006;21(5):1161-1166.

8. Randers E, Erlandsen EJ, Pedersen OL, Hasling C, Danielsen H. Serum cystatin $\mathrm{C}$ as an endogenous parameter of the renal function in patients with normal to moderately impaired kidney function. Clin Nephrol. 2000;54(3):203-209.

9. Nehler MR, Taylor LM Jr, Porter JM. Homocysteinemia as a risk factor for atherosclerosis: a review. Cardiovasc Surg. 1997;5(6):559-567.

10. Wald DS, Law M, Morris JK. Homocysteine and cardiovascular disease: evidence on causality from a meta-analysis. BMJ. 2002;325(7374):1202.

11. Seshadri S, Beiser A, Selhub J, et al. Plasma homocysteine as a risk factor for dementia and Alzheimer's disease. $N$ Engl J Med. 2002;346(7):476-483.

12. Hultberg B, Nilsson K, Isaksson A, Gustafson L. Folate deficiency is a common finding in psychogeriatric patients. Aging Clin Exp Res. 2002;14(6):479-484.

13. Bloemenkamp DG, Mali WP, Tanis BC, et al. The relation between Helicobacter pylori and atherosclerosis cannot be explained by a high homocysteine concentration. Eur J Clin Invest. 2002;32(8):549-555.

14. Ford ES, Smith SJ, Stroup DF, Steinberg KK, Mueller PW, Thacker SB. Homocyst(e)ine and cardiovascular disease: a systematic review of the evidence with special emphasis on case-control studies and nested case-control studies. Int J Epidemiol. 2002;31(1):59-70.

15. Refsum H, Smith AD, Ueland PM, et al. Facts and recommendations about total homocysteine determinations: an expert opinion. Clin Chem. 2004;50(1):3-32.

16. Saibeni S, Lecchi A, Meucci G, et al. Prevalence of hyperhomocysteinemia in adult gluten-sensitive enteropathy at diagnosis: role of B12, folate, and genetics. Clin Gastroenterol Hepatol. 2005;3(6):574-580. 
17. Dickey W, Ward M, Whittle CR, et al. Homocysteine and related Bvitamin status in coeliac disease: effects of gluten exclusion and histological recovery. Scand J Gastroenterol. 2008;43(6):682-688.

18. Shuval-Sudai O, Granot E. An association between Helicobacter pylori infection and serum vitamin B12 levels in healthy adults. $J$ Clin Gastroenterol. 2003;36(2):130-133.

19. Tamura A, Fujioka T, Nasu M. Relation of Helicobacter pylori infection to plasma vitamin B12, folic acid, and homocysteine levels in patients who underwent diagnostic coronary arteriography. Am J Gastroenterol. 2002;97(4):861-866.

20. Danesh J, Peto R. Risk factors for coronary heart disease and infection with Helicobacter pylori: meta-analysis of 18 studies. BMJ. 1998;316(7138):1130-1132.

21. Borch K, Jonsson KA, Petersson F, Redeen S, Mardh S, Franzen LE. Prevalence of gastroduodenitis and Helicobacter pylori infection in a general population sample: relations to symptomatology and life-style. Dig Dis Sci. 2000;45(7):1322-1329.

22. Borch K, Grodzinsky E, Petersson F, Jönsson K- $\AA$, Mårdh S, Valdimarsson T. Prevalence of coeliac disease and relations to Helicobacter pylori infection and duodenitits in a Swedish adult population sample: a histomorphological and serological survey. Inflammopharmacology. 2001;8(4):341-350.

23. Dixon MF, Genta RM, Yardley JH, Correa P. Classification and grading of gastritis. The updated Sydney system. International workshop on the histopathology of gastritis, Houston 1994. Am J Surg Pathol. 1996;20(10):1161-1181.

24. Alexander J. Dermatitis herpetiformis. In: Rook A, ed. Major problems in dermatology. London: Saunders; 1975:236.

25. Sun YQ, Monstein HJ, Ryberg A, Borch K. Multiple strand displacement amplification of DNA isolated from human archival plasma/serum: identification of cytokine polymorphism by pyrosequencing analysis. Clin Chim Acta. 2007;377(1-2):108-113.

26. Fratiglioni L, Launer LJ, Andersen K, et al. Incidence of dementia and major subtypes in Europe: a collaborative study of population-based cohorts. Neurologic diseases in the elderly research group. Neurology. 2000;54(11 Suppl 5):S10-S15.

27. Ozer B, Serin E, Gumurdulu Y, et al. Helicobacter pylori eradication lowers serum homocysteine level in patients without gastric atrophy. World J Gastroenterol. 2005;11(18):2764-2767.

28. Salles-Montaudon N, Parrot F, Balas D, Bouzigon E, Rainfray M, Emeriau JP. Prevalence and mechanisms of hyperhomocysteinemia in elderly hospitalized patients. J Nutr Health Aging. 2003;7(2):111-116.

29. Kullo IJ, Li G, Bielak LF, et al. Association of plasma homocysteine with coronary artery calcification in different categories of coronary heart disease risk. Mayo Clin Proc. 2006;81(2): 177-182.

30. Sipponen P, Laxen F, Huotari K, Harkonen M. Prevalence of low vitamin B12 and high homocysteine in serum in an elderly male population: association with atrophic gastritis and Helicobacter pylori infection. Scand J Gastroenterol. 2003;38(12):1209-1216.

31. Ilhan N, Kucuksu M, Kaman D, Ilhan N, Ozbay Y. The 677 C/T MTHFR polymorphism is associated with essential hypertension, coronary artery disease, and higher homocysteine levels. Arch Med Res. 2008;39(1):125-130.

32. Lewis SJ, Ebrahim S, Davey Smith G. Meta-analysis of MTHFR 677C-\&T polymorphism and coronary heart disease: does totality of evidence support causal role for homocysteine and preventive potential of folate? BMJ. 2005;331(7524):1053.

33. Refsum H, Nurk E, Smith AD, et al. The Hordaland homocysteine study: a community-based study of homocysteine, its determinants, and associations with disease. J Nutr. 2006;136(6 Suppl):1731S-1740S.

34. Santarelli L, Gabrielli M, Cremonini F, et al. Atrophic gastritis as a cause of hyperhomocysteinaemia. Aliment Pharmacol Ther. 2004;19(1):107-111.

35. Leung WK, Ma PK, Choi PC, et al. Correlation between Helicobacter pylori infection, gastric inflammation and serum homocysteine concentration. Helicobacter. 2001;6(2):146-150.

36. Wald NJ, Watt HC, Law MR, Weir DG, McPartlin J, Scott JM. Homocysteine and ischemic heart disease: results of a prospective study with implications regarding prevention. Arch Intern Med. 1998;158(8):862-867.

37. Arnesen E, Refsum H, Bonaa KH, Ueland PM, Forde OH, Nordrehaug JE. Serum total homocysteine and coronary heart disease. Int J Epidemiol. 1995;24(4):704-709.

38. Stehouwer CD, Weijenberg MP, van Den Berg M, Jakobs C, Feskens EJ, Kromhout D. Serum homocysteine and risk of coronary heart disease and cerebrovascular disease in elderly men: a 10-year follow-up. Arterioscler Thromb Vasc Biol. 1998;18(12): 1895-1901.

39. Bots ML, Launer LJ, Lindemans J, et al. Homocysteine and shortterm risk of myocardial infarction and stroke in the elderly: the Rotterdam study. Arch Intern Med. 1999;159(1):38-44.

40. Homocysteine Studies Collaboration. Homocysteine and risk of ischemic heart disease and stroke: a meta-analysis. Jama. 2002; 288(16):2015-2022.

41. Whincup PH, Refsum H, Perry IJ, et al. Serum total homocysteine and coronary heart disease: prospective study in middleaged men. Heart. 1999;82(4):448-454.

42. Fallon UB, Ben-Shlomo Y, Elwood P, Ubbink JB, Smith GD. Homocysteine and coronary heart disease in the Caerphilly cohort: a 10 year follow up. Heart. 2001;85(2):153-158.

43. Ravaglia G, Forti P, Maioli F, et al. Homocysteine and folate as risk factors for dementia and Alzheimer disease. Am J Clin Nutr. 2005;82(3):636-643. 